\title{
Research on the development of film-induced tourism in Heilongjiang Province
}

\author{
Lanlan Liu',a, Qiang Yu ${ }^{1, b}$ \\ ${ }^{1}$ Harbin University Harbin China \\ aliulanlan_001@163.com, byuqiang0708@163.com
}

Keywords: Film-induced tourism, Development, Research.

\begin{abstract}
Heilongjiang Province is rich in film-induced tourism resources, with the unique natural scenery and local customs and practices, Heilongjiang Province attracted a large number of film and television drama creators to come. The flourishing development of film and television has laid a good foundation for the development of Heilongjiang's film-induced tourism. However, through in-depth investigation, we find that there are still have many problems to be solved in the development of film and television tourism in Heilongjiang. For example, the development of the industrial chain of film and television tourism is not perfect, the participation of social resources is low, the social openness of the feature film and television scenic spots is not enough, the integration of the resources of the film and television base is insufficient, the resources are not concentrated; the film and television tourism item is not concentrated. The purpose of this paper is to analyze the above problems in the development of Heilongjiang film and television tourism, and put forward the corresponding countermeasures and methods.
\end{abstract}

\author{
黑龙江省影视旅游发展问题研究 \\ 刘岗岗1, a , 于强1,b \\ 1哈尔滨学院, 哈尔滨, 中国 \\ aliulanlan_001@163.com, byuqiang0708@163.com
}

关键词: 影视旅游; 发展; 研究

中文摘要. 黑龙江省具有丰富的影视旅游资源, 凭借黑龙江省独特的自然风光和风土人情吸 引了大量影视剧创作者们的到来。影视作品的蓬勃发展为黑龙江影视旅游的发展奠定了良好 的基础。但是, 我们通过深入调研发现黑龙江的影视旅游发展仍然存在很多亟待解决的问题, 比如, 影视旅游产业链发展不健全, 社会资源参与度低; 特色影视景点的社会开放度不够; 影视基地资源整合不足, 资源不集中; 影视旅游项目的经营模式单一等, 本文基于黑龙江省 影视旅游发展中存在的上述问题进行了深入分析并提出了相应对策和方法。

\section{1. 黑龙江省影视旅游发展现状}

黑龙江省影视旅游资源丰富, 从1905年中国第一家电影院开始、中国最早的翻译片和首 部长故事片、中国最早和历史最久的电影节相继诞生于黑龙江。田方、杨亚洲、孙红雷、宋 佳、李冰冰等影视名人来自于黑龙江。著名作家萧红、阿成、迟子建、张雅文一些扎根于黑 龙江的作品成为了影视作品争相演绎的题材。近年来随着《闯关东》、《浴火危城》、《乡 村爱情故事》系列、《黄金时代》、《白日焰火》等优秀影视作品的热播, 黑龙江省独特的 
自然风光、风土人情吸引了影视剧大量忠实观众的到来。目前黑龙江省影视旅游类型多样, 基本覆盖了影视旅游活动的所有类型。奠定了黑龙江省大力发展影视旅游的基础。

\section{2. 黑龙江省影视旅游发展中存在的问题}

\section{1 影视旅游产业链发展不健全}

影视旅游产业链是以行业内某一影视旅游企业为中心点进行链接。作为旅游主体的游客 在影视旅游过程中会接受到来自于不同产业的企业或部门提供的服务。在产业链中会有来自 旅游行政管理机构和行业协会提供的支持和保障; 来自宾馆、餐饮、旅游运输、购物、娱乐 项目相关产业的提供的旅游核心服务，; 来自影视制作单位、各类媒体、通讯、保险、金融 产业的辅助。这个影视旅游产业链是一个复杂的链式结构, 如图1所示。涵盖了旅游活动的吃 住行游娱购各个方面内容。从黑龙江省影视旅游发展的现实情况来看, 黑龙江省的影视旅游 产业链发展有待完善。

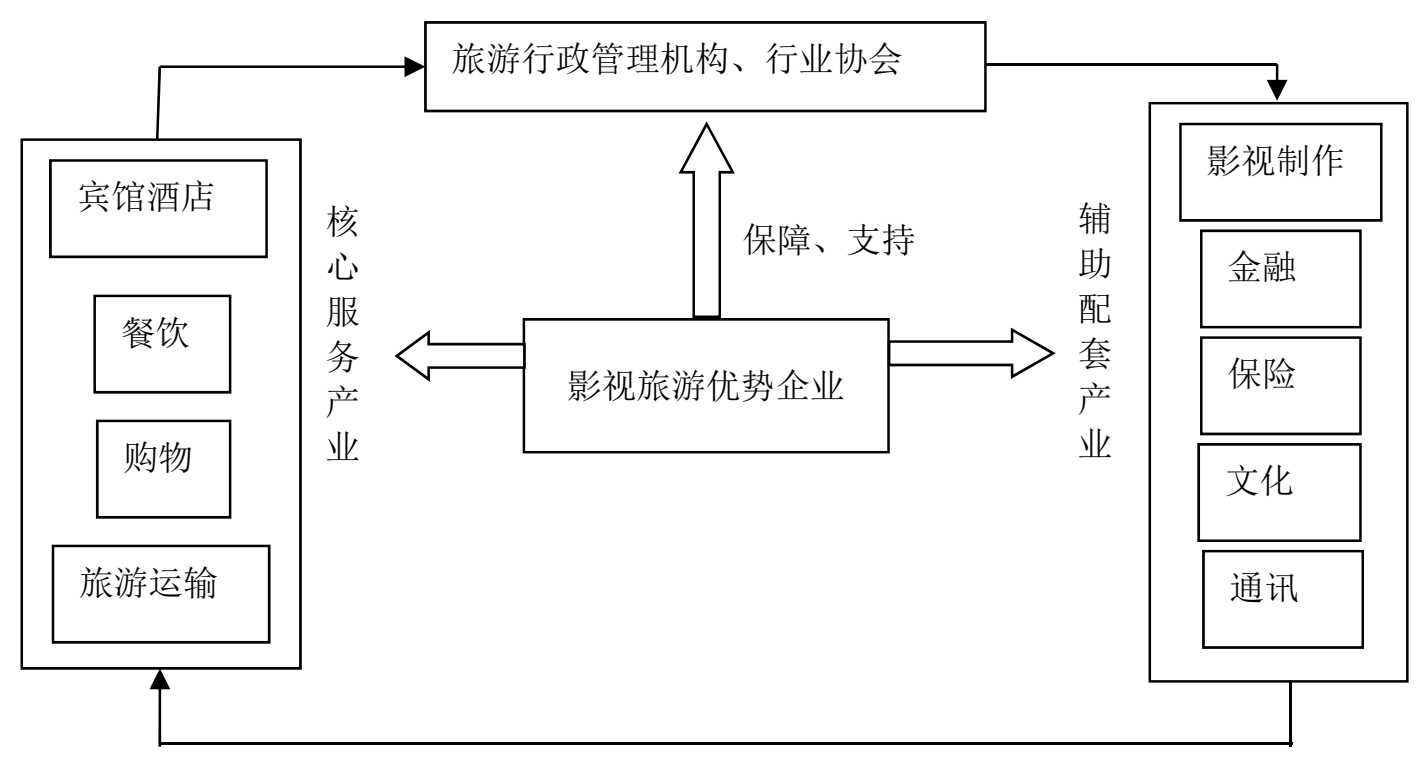

图1.影视旅游产业链结构图

\section{1 .1 行政管理部门的协调能力差}

从影视制作单位来看，影视单位注意挖掘黑龙江省特有的闯关东文化、知青文化、欧陆 文化、北方少数民族文化的创作题材，目前，在省影视管理部门相关政策的扶植下，影视制 作单位的融资、人才等问题都得到了有效地改善。目前, 黑龙江省影视制作单位与行政管理 部门的合作还没有很好地延伸到拍摄后期, 在影视作品的营销、推广, 以及后续影视作品的 衍生产品开发中还需增强与行政管理部门的合作。

\subsection{2 影视旅游项目经营能力差}

从影视旅游经营者来看, 黑龙江省建立了多个影视城、影视基地, 但是同质化现象严重, 各个景区的定位和特色不清晰, 而且景区硬件设施建设以及内涵建设仍缺少统筹和规划。专 门的影视旅游线路开发较少。与影视旅游密切相关的餐饮、住宿、交通等旅游配套设施也没 有充分补充, 在一定程度上阻碍了黑龙江省影视旅游的发展。

\section{2 观光为主、体验度低}

黑龙江省现已建成了多个影视基地、影视城, 影视旅游的形式也主要表现在影视剧取景 地设立指示牌, 标明在此拍摄的剧目、导演、明星等信息, 以观光参观为主。随着体验经济 的到来, 游客更多地希望影视旅游地能提供多方位的参与性服务。目前, 敖其影视城设计了 仿古婚纱摄影和婚庆活动, 根据电视剧《松花江上》的剧情要求, 设计了让游客体验主人公 
程八爷的一天经历。黑河锦河农场影视拍摄基地先后开发了石金河漂流、淘金等项目，增强 了旅游的参与度。但从黑龙江省影视旅游整体来看, 除上述两个景区做得较好外, 大多数景 区还是以观光为主, 个别有参与性设计的环节也过于简单, 无法让游客更多地了解影视剧拍 摄与制作知识, 久而久之, 此类缺乏创意和设计的影视旅游产品势必会影响游客的重游度, 降低影视旅游市场的吸引力。

\section{3 资源整合能力差, 创新不足}

从区域位置来看, 黑龙江省位于祖国的东北边陲, 经济欠发达, 距离经济发达地区距离 远, 虽然黑龙江省积极进行北国风光旅游开发, 冰城夏都的人文和自然风光成为了吸引外地 游客主要到来的主要诉求, 但不可忽视的是游客到黑龙江省的交通成本较高。目前, 黑龙江 省旅游管理部门积极开发不同种类的旅游产品, 如乡村游、工业游、红色游、民俗游等类型。 影视旅游作为新兴的旅游种类, 在发展过程中并没有很好地搭上其他较为成熟的旅游产品的 宣传便利条件。黑龙江省现有的影视城、影视基地大多位于一方, 分布零散, 与其他类型的 旅游的㧢绑发展, 与同类旅游产品的融合与创新极少。黑龙江省影视旅游营销只重影视剧拍 摄时的宣传, 对于影视旅游拍摄前、拍摄中和拍摄后期各环节与影视旅游产业链的联系关注 不多, 这种情况致使黑龙江省影视旅游的发展呈现出的开发模式更多地表现在 “影视剧十影视 城” 上, 在某一影视作品热播后, 与其相关的纪念品、服饰、书籍的后续开发没有跟进, 忽 视了影视旅游产业链的其他部分的收益。

\section{3. 对策研究}

\section{1 资源整合, 做到影视旅游开发的 “链条化”}

影视旅游产业链的构成复杂, 涉及的产业众多。促进影视旅游的发展, 必须将影视旅游 的辅助产业和旅游核心服务产业相结合, 实现横向支持, 纵向融合、综合发展。横向支持是 指影视旅游相关企业要与旅游行政管理机构、金融保险产业、宾馆餐饮等行业积极合作, 形 成和谐发展, 以链条上产业间的整体利益为目标, 在政府的政策法规的引导下, 进行各类资 源和环节的合理整合，保持链条有机联动。纵向融合是指影视旅游产业链条上、下各环节间 的融合, 以促成各产业随着影视旅游的发展而形成良性互动。例如影视旅游发展要在政府引 导下通过影视旅游优势企业进行旅游产品研发, 通过下游辅助部门的配合进行市场延伸, 最 终通过市场的检验不断完善影视旅游产品的定位和功能。综合发展是指通过影视旅游产品的 核心作用, 带动核心服务产业集群、完善辅助产业集群, 发展衍生产业集群。例如因为黑龙 江省各类资源的差异性及旅游企业的经济能力的限制, 单一的对影视旅游这一类型进行旅游 开发, 对游客的吸引力是有限的。故将多种形式的旅游类型加以整合, 有利于使旅游形成规 模化, 增强旅游吸引力。黑龙江省独特的位置和物候条件造就了黑龙江省特有的原始、神奇 的大冰雪、大农场、大界江、大湖泊、大森林、大湿地等自然景观。音乐文化、欧陆文化、 闯关东文化、知情文化、北方少数民族文化也是吸引全国旅游者的优质人文资源。因此在发 展影视旅游的同时, 不断改善休闲娱乐、购物、酒店、旅行社的接待环境, 提供就业岗位, 加强交通等基础设施建设, 促进影视旅游与黑龙江省的民俗、观光、乡村旅游的结合。围绕 文化、冰雪、生态等旅游产品体系, 不断推出影视旅游组合旅游精品。围绕综合发展积极设 计主题旅游线路, 深入挖掘内涵, 在游客获得偷悦的同时, 扩大影响, 促进区域经济发展。

\section{2 加强对外宣传力度, 做到营销手段 “创新化”}

营销活动对影视旅游的发展起着至关重要的作用，根据影视旅游发展的阶段性特征制定 不同的宣传策略, 运用会员制营销、免租营销、体验营销、个性化营销等多种手段对宣传活 动进行创新将进一步促进影视旅游的发展。

3.2.1 以政府为主导, 加大黑龙江省影视旅游地的宣传。 
作为旅游活动的新兴形式, 黑龙江省影视旅游需求有限, 营销渠道狭窄, 营销平台缺乏。 因此, 有必要进一步加强报刊、电视、网站等渠道的宣传力度, 搭建营销平台, 及时披露在 黑龙江省拍摄的影视剧动态, 通过专栏集中展示与影视拍摄地相关的吃住行游娱购得各类信 息，吸引更多的旅游者的到来，从而促进当地旅游业朝着健康方向发展。

3.2 .2 积极与旅游景区、酒店、旅行社进行合作与宣传。

任何旅游产品的开放与设计都离不开全行业的支持与协调。影视旅游的发展必须通过各 地景区、景点间的相互推介开展营销。另一方面, 给予旅行社相应优惠折扣, 将部分影视旅 游项目纳入到常规旅游线路中，也将大大促进影视旅游的发展。

\subsection{3 创新营销途径和手段。}

充分利用哈尔滨冰雪电影节、中国・哈尔滨之夏国际文化旅游节、冰雪节、哈夏音乐会、 哈洽会、湿地节、啤酒节和地方系列节庆活动开展影视旅游营销, 邀请明星参与, 利用明星 效应, 积极组织游客市民参与其中, 通过广告软植入, 对黑龙江省影视旅游产品进行促销。

\section{3 适应体验经济需要, 打造影视旅游产品 “精品化”}

为了更好地利用黑龙江省优秀影视作品的影响力, 黑龙江省旅游管理部门可以黑龙江省 影视剧地图为核心，将黑龙江省的优秀影视作品中涉及到的优质旅游地串联成线，使游客在 优美的自然风貌中融入影视剧的情感体验。与传统旅游相比, 体验性是影视旅游的重要特性。 作为拍摄地, 各影视基地、影视城可根据游客的需要, 参与影视拍摄、以游客为主创参与到 影视剧场景的拍摄, 并制作成光盘留念。各部门联动, 积极开发与影视剧相关的影视旅游线 路, 如针对《闯关东》的热播, 进行闯关东放山游、寻根游、采金游等多种类型的旅游线路, 并且在旅游线路的设定具有闯关东特色的文化表演、饮食、建筑、市井文化的展现，让游客 在视觉、听觉、味觉上获得综合的体验。

\section{致谢}

本文为哈尔滨学院青年硕士基金项目《黑龙江省影视旅游发展问题研究》的阶段性成果 之一。

\section{References}

[1] Pei-Ti Chen, Analysis of Product Placement in Film-induced Tourism: Case Study of Summer Times, The Anthropologist ,vol.108,pp.75-85, 2017.

[2] Justyna Bąkiewicz; Anna Leask; Paul Barron; Tijana Rakić, Management Challenges at Film-Induced Tourism Heritage Attractions, Tourism Planning \& Development, vol.07,pp.548-566,2017.

[3] Niki Macionis; Noe"lle O'Connor, How can the film-induced tourism phenomenon be sustainably managed?, Worldwide Hospitality and Tourism Themes, vol. (5) ,pp.173-178, 2011.

[4] Fei Qiao; Yeonhee Choi; Timothy J. Lee, Assessing feasibility of film-induced tourism: the case of Singapore, International Journal of Tourism Sciences, vol.10,pp. 93-105,2016. 